\title{
CARACTERIZAÇÃO CELULAR DA HEMOLINFA DE FÊMEAS INGURGITADAS DE Amblyomma sculptum
}

(Cellular characterization of hemolymph in ingurgitated females of Amblyomma sculptum)

\begin{abstract}
Andressa Aparecida de Lima Reis, Debora Azevedo Borges, Marisa Beatriz da Silva Rocha, Rayane Christine Pereira de Assis, Diefrey Ribeiro Campos, Melina Cardilo Campos Alves, Barbara Rauta de Avelar, Fabio Barbour Scott
\end{abstract}

Universidade Federal Rural do Rio de Janeiro, Rio de Janeiro, Brasil.

*Correspondência: andressareismv@gmail.com

RESUMO: O carrapato Ambyomma sculptum, encontrado as várias regiões do Brasil, é conhecido como "carrapato estrela" ou "carrapato do cavalo" e parasita animais domésticos, silvestres e humanos, sendo o principal transmissor de Rickettsia rickettsii, agente etiológico da Febre Maculosa Brasileira. Possui grande importância veterinária por causar diversos prejuízos aos seus hospedeiros. Estudos sobre sistema imunológico de carrapatos buscam avaliar alterações na resposta celular hemolinfática que faça entender a imunologia e fisiologia envolvida nos mecanismos de controle e resistência. O objetivo deste trabalho foi caracterizar quantitativamente e morfologicamente os hemócitos da hemolinfa de fêmeas ingurgitadas de $A$. sculptum. A hemolinfa foi coletada por uma perfuração da cutícula na parte dorsal do carrapato e depositada em lâmina de vidro para confecção dos esfregaços que foram corados por solução de Giemsa. Foi realizada a contagem diferencial de hemócitos com base na morfologia observada em microscópio óptico em aumento de 1000 vezes, através da identificação das 100 primeiras células encontradas. A avaliação dos tamanhos de cada célula e de seus componentes foi realizada por leitura das lâminas confeccionadas para contagem diferencial dos hemócitos com o auxílio de um microscópio óptico com luz polarizada. A contagem total de hemócitos foi realizada com auxílio de microscópio óptico e Câmara de Neubauer. A caracterização celular revelou que o carrapato $A$. sculptum apresenta média de 1024 céls $/ \mu \mathrm{L}$ e seis tipos celulares que se distribuem de forma distinta na hemolinfa. Os granulócitos foram os hemócitos mais frequentes (78\%), seguidos de plasmatócitos (10\%), prohemócitos (6\%), esferulócitos (5\%), oenocitóide (1\%) e adipohemócito com menos de $1 \%$ de frequência. De acordo com as características morfológicas os granulócitos foram descritos com tamanho médio de $22 \times 19 \mu \mathrm{m}$, sendo células de tamanhos variados e de formas arredondadas a elípticas, com citoplasma coberto de grânulos. Os plasmatócitos se apresentaram polimórficos com citoplasma vacuolizado ou granular e foi o grupo com maior variação de forma e tamanho com medidas médias de $24 \times 10 \mu \mathrm{m}$. Os prohemócitos foram o menor tipo celular observado medindo em média $13 \times 11 \mu \mathrm{m}$, se apresentando em formato arredondado, com núcleo central e escasso citoplasma. Os esferulócitos caracterizaram-se como células arredondadas (tamanho médio de $22 \times 20 \mu \mathrm{m}$ ) com estruturas presentes de forma abundante no

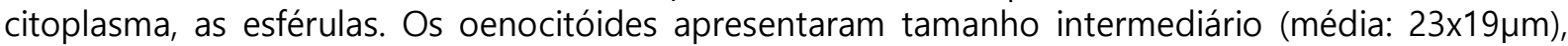
com forma arredondada, margens irregulares e citoplasma com granulações refráteis e aspecto esponjoso. Os adipohemócitos, raramente encontrados, são células de tamanho variável, margens citoplasmáticas irregulares, vesículas refringentes no citoplasma e a quantidade observada não foi suficiente para realização da conferência das medidas com segurança estatística. Conclui-se que a partir da microscopia óptica foi possível determinar o valor médio do total de hemócitos circulantes, classificados morfologicamente como granulócitos, plasmatócitos, prohemócitos, esferulócitos, oenocitóides e adipohemócitos, e determinar a frequência média de cada hemócito na hemolinfa de $A$. sculptum, onde os granulócitos são o tipo mais frequentes.

Palavras-chave: carrapatos; célula; hemócitos.

Agradecimentos: LQEPV; CAPES; CNPq; FAPUR.

Aprovação por Comitê de Ética: CEUA IV/UFRRJ 7699190418. 